\title{
Effects of Interactional Context on Intentional Communicative Acts of Toddlers: Focused on Free Play and Book Reading
}

\author{
Da Ye Lee ${ }^{a}$, YoonKyoung Lee ${ }^{b}$ \\ ${ }^{a}$ Department of Speech-Language Pathology, Graduate School of Public Health E Science, Hallym University, Chuncheon, Korea \\ ${ }^{b}$ Division of Speech Pathology and Audiology, Hallym University, Chuncheon, Korea
}

Correspondence: YoonKyoung Lee, $\mathrm{PhD}$ Division of Speech Pathology and Audiology, Hallym University, 1 Hallimdaehak-gil, Chuncheon 24252, Korea

Tel: $+82-33-248-2219$

Fax: +82-33-256-3420

E-mail: ylee@hallym.ac.kr

Received: July 20, 2018

Revised: August 17, 2018

Accepted: August 25, 2018

\begin{abstract}
Objectives: The purpose of this study was to investigate the influence of the interactional context on the intentional communication acts of toddlers. Methods: A total of 30 toddlers aged 12-30 months participated in the study. The participants were classified into three age groups: 12-18 months, 19-24 months, and 25-30 months. The behavior samples of the participants were collected in both free play and book reading contexts; and the total frequency of intentional communicative acts was measured, as well as the frequency of communicative acts according to the communicative functions. Results: The total frequency of intentional communicative acts increased significantly according to age, but there was no significant interaction effect with the interactional context. The frequency of communicative acts according to the communicative function showed significant interaction effects between age and interactional context. The frequency of behavior regulation was significantly higher during free play than book reading. On the other hand, joint attention was significantly greater during book reading than in the context of free play. The interaction effects between the communicative functions and the interactional context increased depending on age. Conclusion: The results of this study help us to understand that the intentional communication acts of toddlers have been affected by interactional contexts. Interactional contexts have to be considered for assessing the communicative acts of the toddlers.
\end{abstract}

Keywords: Intentional communicative acts, Interactional context, Free play, Book reading
의도적 의사소통행동(intentional communication acts)은 상대 방에게 의도를 전달하기 위한 행동으로, 언어가 발달되기 이전인 영아기의 의도적 의사소통행동 발달은 이후의 언어를 통한 의사소 통발달의 기반이 된다(Calandrella \& Wilcox, 2000; Choi \& Lee, 2018; Lee \& Lee, 2016). 따라서 언어 이전기부터 시작되는 의도적 의사소통행동 발달은 이후의 언어발달을 예측하도록 하며, 이를 통해 언어발달지연 여부를 조기에 판별하고 나아가 조기개입을 촉 진하는 데 중요한 의미를 갖는다.

의도적 의사소통행동 발달은 의도적 행동이 상대방에게 어떠한 영향을 미쳤는지를 중심으로 살펴보는 의사소통기능의 측면과, 이 러한 의도를 전달하기 위해 어떠한 수단을 사용하였는지를 중심으
로 하는 의사소통수단 측면을 중심으로 연구되어 왔다(Calandrella \& Wilcox, 2000; Cho \& Lee, 2010; Lee, 2006; Lee \& Lee, 2016; Wetherby \& Prizant, 2002). 이 중 의사소통기능은 행동이 상대방 에게 미치는 효과와 관련되어 의도적 의사소통행동 발달의 주요 지표가 된다.

영아가 의도를 상대방에게 전달하는 의도적 의사소통행동은 9 개월을 전후하여 출현하기 시작한다(Bates, Camaioni, \& Volterra, 1975). Bates 등(1975)에 의하면 4개월에서 8개월 정도의 영아들은 원하는 결과를 중심으로 의도를 드러내기 시작하나 아직은 결과 를 향한 행동일 뿐 의도를 다른 사람에게 전달하는 행동을 보이지 는 않는다. 때문에 영아가 보이는 행동을 통해 주변 사람들이 영아 
의 의도를 이해해야 한다. 그러나 이 시기를 지나면서 점차 자기행 동이 상대방에게 미치는 영향을 이해하게 되고, 원하는 결과를 얻 기 위하여 상대방에게 자기 생각, 즉 의도를 전달하는 행동을 보이 기 시작한다.

이렇게 시작된 의도적 의사소통행동은 점차 다양한 기능으로 분 화되기 시작한다. 영아기의 의사소통기능의 발달은 여러 연구자들 에 의해 다양한 분류기준으로 연구되어 왔으나(Chapman, 2000; Dore, 1975; Halliday, 1975), 그 중에서도 Bruner (1981)가 제시한 기준에 따라의사소통기능을 행동통제, 사회적 상호작용, 동시주의 기능의 세 가지 범주로 나누어 발달을 살펴본 연구들(Cho \& Lee, 2010; Lee, 2006; Lee \& Lee, 2016; Wetherby, Cain, Yonclas, \& Walker, 1988)은 영아들이 보인 의도적 의사소통행동을 유목화하 여 줌으로써 영아기 의도적 의사소통발달을 더 쉽고 명료하게 이해 할 수 있게 한다. 이 분류기준을 사용한 국내외 연구들은 모두 공 통적으로 자기가 원하는 결과를 얻기 위해 다른 사람의 행동을 조 절하는 행동통제적 기능이 가장 먼저 발달되기 시작하며, 엇비슷 한 시기에 다른 사람의 관심을 유도하고자 하는 사회적 상호작용 기능과 다른 사람의 관심을 제 3 의 다른 사물이나 사건으로 이끌고 자 하는 동시주의(joint attention, 공동관심) 기능이 출현한다고 보 고하였다. 세 범주의 의사소통기능 모두 대체로 12 개월을 전후해서 출현하여 출현시기에서는 큰 차이가 없으나 주로 사용되는 시기에 서는 명백한 차이를 보인다. 주로 12 개월을 전후한 어린 시기에는 행동통제적 기능이 월등하게 많이 사용되다가 언어가 주된 의사소 통수단으로 자리를 잡기 시작하는 18 개월에서 24 개월 사이에 동시 주의 기능의 사용빈도가 유의하게 증가한다(Lee \& Lee, 2016; Wetherby et al., 1988).

의사소통기능이 연령에 따라 다른 양상으로 발달되는 데에는 언 어발달은 물론 사회적 능력이나 인지능력과 같은 여러 요인이 영향 을 미칠 수 있다. 다른 사람들과 상호작용을 통해 다양한 사회적 기 술을 습득하고 언어발달을 통해 이를 표현할 수 있는 능력이 발달 됨에 따라 표현하는 의사소통기능도 더욱 다양해지는 것이다. 그러 나 이러한 영아들의 개인 내적 요인만이 아니라 상호작용 상대방의 행동이나, 그리고 상호작용 맥락과 같은 환경적 요인도 역시 영아의 의사소통 행동에 영향을 미친다(Wetherby et al., 1988; Yont, Snow, \& Vernon-Feagans, 2003). 그 중에서도 상호작용 맥락은 상호작용 대상이 제한된 영아들의 의사소통행동에 중요한 영향을 미친다.

상호작용 맥락(interactional context)이 영아의 의사소통발달에 미치는 영향은 주로 책읽기와 놀이 상황을 중심으로 연구되어 왔 다(Kim, 2000; Kim, Lee, \& Lee, 2015; Yont et al., 2003). 이는 이 두 상황이 모두 영아들에게 친숙한 상황이므로 짧은 시간 동안 의사
소통행동을 유도하기 용이할 뿐만 아니라 자연스러운 의사소통행 동을 쉽게 관찰할 수 있도록 하기 때문이다. 또한 영아들이 가장 많 이 참여하는 상호작용 맥락이므로 각각의 맥락에서 영아의 행동 을 확인하는 것이 큰 의미를 주기 때문이기도 하다(Hoff, 2006). $\operatorname{Kim}$ (2000)은 9-24개월 영아와 양육자 20쌍을 대상으로 책읽기, 놀이, 일상 상황에서 영아와 양육자의 언어적, 비언어적 상호작용 행동을 살펴보았으며, 영아와 양육자 행동 모두 책읽기와 놀이, 두 조건에 따라 달라졌다고 보고하였다. 즉, 영아는 책읽기 상황에서 는 모방, 명명과 같은 언어적 상호작용을, 놀이 상황에서는 자발적, 연속적 행동과 같은 비언어적 상호작용 유형을 더 많이 보였으며, 양육자는 놀이와 일상 상황에서는 지시하기, 질문하기를 많이 하 고 책읽기 상황에서는 설명하기, 질문하기를 많이 하였다. 연구자 는 이러한 결과에 대해 놀이 상황에 비해 책읽기 상황은 언어를 매 개로 하기 때문에 언어적 상호작용이 많이 나타난다고 설명하였다.

Yont 등(2003)도 Kim (2000)과 비슷한 연구를 통해 유사한 결과 를 보고하였다. 이들은 $\operatorname{Kim}$ (2000)보다 더 어린 12개월 영아와 양 육자 25 쌍을 대상으로 책읽기와 놀이 상황에서 의사소통행동을 비교하였다. 연구자들은 의사소통기능 유형과 수단을 중심으로 살 펴보았는데, 영아는 책읽기 상황에서 명명하기와 반응하거나 개시 하는 형태의 동시주의 행동을 유의하게 많이 보인 반면, 놀이 상황 에서는 몸짓을 통해 상대방의 관심을 유도하거나 현재 발생하는 사 건으로 주의를 유도하는 행동을 많이 보였다. 연구자들은 이러한 결과를 통해 책읽기 상황에서는 함께 주의를 기울이고 있는 것에 대해 논의하는 형태의 상호작용이 많이 발생하고, 놀이 상황에서 는 언어보다는 몸짓을 동반한 형태로 양육자의 관심을 유도하는 행동을 많이 보인다고 논의하였다.

$\operatorname{Kim}$ (2000), Yont 등(2003)이 일반 영아를 대상으로 연구한 반면 $\operatorname{Kim}$ 등(2015)은 18-24개월 말 늦은 영아와 어머니 12쌍, 일반 영아 와 어머니 12 쌍을 대상으로 책 읽기, 놀이 상황에서 보인 의사소통 행동을 비교하여 상호작용 맥락이 영아의 의사소통행동에 미치는 영향을 살펴보았다. 이들은 영아와양육자의 의사소통행동과 기능 유형을 분석하였는데, 영아의 의사소통행동 빈도는 두 집단 모두 책읽기 상황에서 더 높게 나타났으며, 책읽기 상황에서 놀이 상황 보다 명명, 진술, 모방, 질문, 반응하기가 많이 나타났고, 놀이 상황 에서는 요구하기가 많이 나타났다고 하였다. 그리고 영아의 의사소 통행동이 양육자의 의사소통행동과 유의하게 관계되었다고 보고 하였다.

앞에서 살펴 본 선행연구들은 영아들의 의사소통행동이 상호작 용 맥락에 따라 달라질 수 있음을 확인하였으나 세 연구 모두 영아 집단을 한 집단으로 연구하여 이와 같은 상호작용 맥락이 연령에 
따라서는 어떻게 영향을 미치는지에 대해서는 보고하지 않았다. 상 호작용의 맥락적 조건이 언어나 의사소통 발달에 미치는 영향은 연령에 따라 달라질 수 있다(Hoff, 2006; Wetherby, \& Rodriguez, 1992). 따라서 상호작용 맥락이 영아의 연령에 따라 미치는 영향이 달라지는지를 확인하는 것은 각 시기별로 의사소통 평가나 중재를 계획하는 데에 시사점이 클 것이다. 이상과 같은 배경하에 본 연구 에서는 의사소통발달이 활발하게 이루어지는 12-30개월의 영아를 세 연령 집단으로 나누어 연령에 따라 책읽기와 놀이, 두 가지 맥락 이 의사소통행동에 어떻게 영향을 미치는지를 확인하고자 하였다.

\section{연구방법}

\section{연구참가자}

연구에는 서울, 경기 및 강원지역에 거주하는 12-30개월 사이의 영아 30명이 참가하였다. 영아는 12-18개월, 19-24개월, 25-30개월의 세 집단으로 구분하여 각각 10 명씩 표집하였다. 모든 영아는 영아선 별·교육진단검사(Developmental Assessment for the Early Intervention Program Planning, DEP; Jang, Seo, \& Ha, 2009)를 실시하 여 전체 점수와 의사소통영역 점수가 25 백분위수 이상에 해당하는 경우만 포함하였다. 본 연구에 참여한 영아 정보는 Table 1과 같다.

\section{자료수집 도구}

놀이 상황에서는 0-3세 영아가 일상에서 자주 접하여 익숙하게 느끼는 소꿉놀이(인형, 컵 2개, 숟가락 2개, 접시 2개, 우유병 2개, 후 라이팬, 뚜껑, 주걱, 믹싱볼, 뒤집개)와 목욕놀이(인형, 욕조, 샴푸, 샤워볼, 칫솔, 치약, 수건) (Lee \& Lee, 2013)를 사용하였으며, 책읽 기 상황에서는 2012년 어린이도서연구회 0-3세 그림책 추천목록 을 참고하여 ‘달님 안녕', '사과가 쿵, '두드려 보아요' '엄마랑 뽀뽀', ‘뭐 하니', '응가하자, 끙끙' 6 권을 선정하여 사용하였다.

Table 1. Participants' information

\begin{tabular}{lccc}
\hline & \multicolumn{3}{c}{ Age group } \\
\cline { 2 - 4 } & $\begin{array}{c}12-18 \mathrm{mo} \\
(\mathrm{N}=10)\end{array}$ & $\begin{array}{c}19-24 \mathrm{mo} \\
(\mathrm{N}=10)\end{array}$ & $\begin{array}{c}25-30 \mathrm{mo} \\
(\mathrm{N}=10)\end{array}$ \\
\hline $\begin{array}{l}\text { Chronological age }(\mathrm{mo}) \\
\text { DEP score }\end{array}$ & $14.90 \pm 2.02$ & $21.10 \pm 1.85$ & $26.90 \pm 1.59$ \\
Communication & & & \\
& $73.17 \pm 21.07$ & $73.69 \pm 22.65$ & $68.66 \pm 29.22$ \\
Total & $(27.30-99.00)$ & $(35.90-99.00)$ & $(27.30-99.00)$ \\
& $79.53 \pm 20.74$ & $74.35 \pm 27.08$ & $76.83 \pm 21.96$ \\
& $(28.90-99.00)$ & $(30.50-99.00)$ & $(35.10-99.00)$ \\
\hline
\end{tabular}

Values are presented as mean $\pm S D$ (range).

$\mathrm{DEP}=$ Developmental Assessment for the Early Intervention Program Planning (Jang, $\mathrm{SeO}, \& \mathrm{Ha}, 2009)$.

\section{자료수집 절차}

자료수집은 영아의 거주지를 연구자가 방문하여 실시하였다. 자 료수집을 시작하기 전에 연구자는 양육자에게 연구목적 및 절차 에 대해 설명을 하고, 양육자로부터 연구동의서에 서명을 받았다. 그리고 양육자에게 기본정보 조사를 위한 설문지와 전반적 발달검 사인 $\mathrm{DEP}$ 를 작성하도록 하였다. 양육자가 설문지와 $\mathrm{DEP}$ 를 작성하 는 동안 연구자는 영아와 친숙해지는 시간을 가졌다.

영아와 어느 정도 친밀감이 형성된 후 책읽기와 놀이를 통해 자 료수집을 시작하였다. 상호작용 맥락의 순서 효과를 통제하기 위 하여 상호작용 맥락 제시 순서를 교차균형화(counter-balanced)하 여 1 명의 영아에게는 놀이를, 1 명의 영아에게는 책읽기를 먼저 시 작하도록 설계하였으나, 연령 집단별 2명씩을 대상으로 한 예비연 구에서 대부분의 영아가 놀이를 먼저 실시하는 경우에는 행동이 통제되지 않아 이후 책읽기 활동이 제대로 진행되지 않았다. 따라 서 절차를 수정하여 모든 영아에게 책읽기를 먼저 실시한 후 놀이 를 진행하였다.

양육자마다 상호작용 방식에 차이가 있고 영아의 의사소통행동 은 상대자의 상호작용 방식에 따라 달라지므로(Lee \& Seol, 2012) 이를 최대한 통제하기 위하여 상호작용 상대자로 연구자가 직접 참 여하였다. 영아들이 아직 어리기 때문에 양육자를 옆에 있는 것은 허용하였으나 양육자의 행동이 영아 행동에 영향을 주지 않도록 옆에서 지시를 하거나 개입하는 행동은 하지 않도록 미리 지시하였 으며, 영아가 양육자에게 상호작용을 시도하는 경우에는 자연스럽 게 반응해주도록 안내하였다.

상호작용 시 상대자의 행동에 따라 영아의 의도적 의사소통행동 의 빈도나 기능이 달라질 수 있으므로, 선행연구의 지침에 따라 (Lee \& Lee, 2016; Wetherby \& Prizant, 2002) 연구자의 행동도 먼 저 질문을 하거나 지시하는 행동은 하지 않고 영아가 관심을 보이 는 것에 함께 관심을 보이고, 개시한 행동에 자연스럽게 반응해주 도록 하였다. 또한 연구자의 행동이 연구결과에 영향을 주지 않도 록 두 상호작용 맥락 조건에 동일하게 적용하였다. 책읽기와 놀이 중간에는 약 5-10분 정도의 휴식 시간을 갖도록 하였다.

두 조건 각각 최소 15 분 이상 진행하였으며, 영아와 연구자의 행 동을 관찰할 수 있는 곳에 캠코더(Samsung VM-HMX20C)를 설 치하여 전 과정을 녹화하였다.

\section{자료분석 및 측정}

책읽기와 놀이 각각에서 연속적으로 10 분씩 발췌하여 분석하였 다. 책읽기의 경우 영아가 책에 관심을 갖고 검사자와 적극적으로 상호작용하기 시작하는 시점부터 10 분을 포함하였으며, 놀이는 놀 
이를 시작하는 시점과 끝나는 시점을 제외하고 적극적으로 놀이가 진행되는 10 분을 포함하였다.

영아의 의도적 의사소통행동은 Lee와 Lee (2016)의 기준과 정의 (Appendix 1)에 따라 분석한 후, 전체 빈도와 의사소통행동 기능 유형별 빈도로 측정하였다.

\section{신뢰도}

자료분석에 대한 신뢰도는 두 평가자 간 일치도로 산출하였다. 제1평가자는 연구자, 제2평가자는 언어병리학을 전공하는 대학원 생이었으며, 신뢰도 평가 전에 미리 분석기준과 방법에 대해 교육과 훈련을 진행하였다. 훈련 과정에서 서로 분석결과에 차이가 있는 경우에는 논의하고 합의하는 시간을 가졌으며, 1 명의 영아 자료에 대해 두 사람 간에 $90 \%$ 이상의 일치를 보인 후에 독립적으로 분석 하였다. 신뢰도 평가는 각 월령별로 영유아 2명씩, 총 6명(전체 참가 자의 $20 \%$ )을 임의로 선정하여 실시하였으며, 두 평가자 간에 일치 한 빈도수를 일치 빈도수와 불일치 빈도수를 합한 값으로 나눈 후 100 을 곱하여 일치도를 산출하였다. 측정 결과 전체 의도적 의사소 통행동과 의사소통기능에 대한 일치도는 $91.75 \%$ 이었다.

\section{자료의 통계분석}

측정된 자료에 대해 IBM SPSS Statistics version 23 프로그램을 사용하여 통계분석을 실시하였다. 연령과 상호작용 맥락에 따른 전체 및 기능 유형별 의도적 의사소통행동의 차이를 확인하기 위 하여 연령(3) $\times$ 상호작용 맥락(2) $\times$ 의사소통기능(3)을 변인으로 반

Table 2. Results of the descriptive statistics

\begin{tabular}{lcccc}
\hline & Age group & Book reading & Play & Total \\
\hline Behavior & $12-18 \mathrm{mo}$ & $7.90 \pm 4.25$ & $7.50 \pm 3.53$ & $7.70 \pm 3.44$ \\
regulation & $19-24 \mathrm{mo}$ & $4.10 \pm 4.45$ & $11.00 \pm 3.94$ & $7.55 \pm 1.67$ \\
& $25-30 \mathrm{mo}$ & $2.50 \pm 2.22$ & $8.50 \pm 2.41$ & $5.50 \pm .94$ \\
& Total & $4.83 \pm 4.31$ & $9.00 \pm 3.57$ & $6.91 \pm 2.42$ \\
Social inter- & $12-18 \mathrm{mo}$ & $1.40 \pm .84$ & $1.60 \pm 1.42$ & $1.50 \pm .91$ \\
action & $19-24 \mathrm{mo}$ & $3.40 \pm 3.06$ & $2.90 \pm 1.85$ & $3.15 \pm 1.79$ \\
& $25-30 \mathrm{mo}$ & $2.80 \pm 2.57$ & $5.00 \pm 2.58$ & $3.90 \pm 1.88$ \\
& Total & $2.53 \pm 2.43$ & $3.16 \pm 2.40$ & $2.85 \pm 1.84$ \\
Joint atten- & $12-18 \mathrm{mo}$ & $4.90 \pm 4.35$ & $1.90 \pm 2.42$ & $3.40 \pm 3.20$ \\
tion & $19-24 \mathrm{mo}$ & $12.00 \pm 3.46$ & $5.20 \pm 3.22$ & $8.60 \pm 2.53$ \\
& $25-30 \mathrm{mo}$ & $20.10 \pm 6.06$ & $11.90 \pm 4.62$ & $16.00 \pm 4.01$ \\
& Total & $12.33 \pm 7.80$ & $6.33 \pm 5.44$ & $9.33 \pm 6.15$ \\
Total & $12-18 \mathrm{mo}$ & $14.20 \pm 5.92$ & $11.00 \pm 5.86$ & $12.50 \pm 5.97$ \\
& $19-24 \mathrm{mo}$ & $19.50 \pm 6.22$ & $19.10 \pm 4.67$ & $19.30 \pm 5.36$ \\
& $25-30 \mathrm{mo}$ & $25.40 \pm 7.36$ & $25.40 \pm 4.22$ & $25.40 \pm 5.84$ \\
& Total & $19.70 \pm 7.83$ & $18.50 \pm 7.67$ & $19.10 \pm 7.71$ \\
\hline
\end{tabular}

복측정된 삼원혼합분산분석(repeated three-way mixed ANOVA) 을 실시하였다. 연령은 피험자 간 요인(between-subject factors)으 로, 상호작용 맥락과 의사소통기능은 피험자 내 요인(within-subject factors)으로 하였다. 삼원혼합분산분석을 실시한 후에 주효과 및 상호작용 효과가 나타나는 경우에는 두 대응표본 $t$-검정으로 사 후분석을 실시하였다.

\section{연구결과}

연령과 상호작용 맥락 간의 영아의 의사소통행동 기능별 빈도 기술통계 결과는 Table 2, 삼원혼합분산분석(three-way mixed ANOVA) 결과는 Table 3 과 같다.

먼저 연령, 의사소통기능 유형, 상호작용 맥락에 따른 결과를 보 면, 연령에 따라서는 의도적 의사소통행동이 12-18개월에 12.5 회, 19-24개월에 19.3회, 25-30개월에 25.4회로 유의한 주효과 $\left(F_{(2,54)}=\right.$ $17.390, p<.001)$ 가 나타났으며, 의사소통기능 유형에 따라서도 행 동통제기능이 6.91회, 사회적 상호작용기능이 2.85회, 동시주의기 능이 9.33회로 유의한 주효과 $\left(F_{(2,54)}=59.678, p<.001\right)$ 가 나타났다. 각각에 대한 사후검정 결과, 연령에 따른 주효과는 세 연령 집단 간 에 모두 유의한 차이로 인해 나타났으며, 의사소통기능 유형에 따 른 주효과는 행동통제 빈도가 사회적 상호작용 빈도에 비해, 동시 주의 빈도가 사회적 상호작용 빈도에 비해 유의하게 높은 것으로 인해 나타났다. 반면 상호작용 맥락에 따라서는 책읽기에서 19.70 회, 놀이에서는 18.50 회로 유의한 주효과가 관찰되지 않았다.

각각의 변수 간의 상호작용 효과를 살펴본 결과, 연령 $\times$ 의사소 통기능 $\left(F_{(4,54)}=27.284, p<.001\right)$, 상호작용 맥락 $\times$ 의사소통기능 $\left(F_{(2,54)}=30.361, p<.001\right)$, 연령 $\times$ 의사소통기능 $\times$ 상호작용 맥락 $\left(F_{(4,54)}=4.565, p<.01\right)$ 간에 유의한 상호작용 효과가 나타났으나 연 령 $\times$ 상호작용 맥락간의 상호작용 효과는 나타나지 않았다.

연령 $\times$ 의사소통기능 간의 상호작용은 $12-18$ 개월에는 행동통제

Table 3. Results of three-way mixed ANOVA

\begin{tabular}{lcc}
\hline Source & $F$ & $p$-value \\
\hline Main effects & $17.390^{* * *}$ & .000 \\
$\quad$ Age & 1.066 & .311 \\
Interactional context & $59.678^{* * *}$ & .000 \\
Communicative functions & & \\
Interaction effects & .750 & .482 \\
Agex interactional context & $27.284^{* * *}$ & .000 \\
Agex communicative functions & $30.361^{* * *}$ & .000 \\
Interactional context×communicative functions & $.565^{* *}$ & .003 \\
Age xinteractional context×communicative functions & 4.50 \\
\hline
\end{tabular}



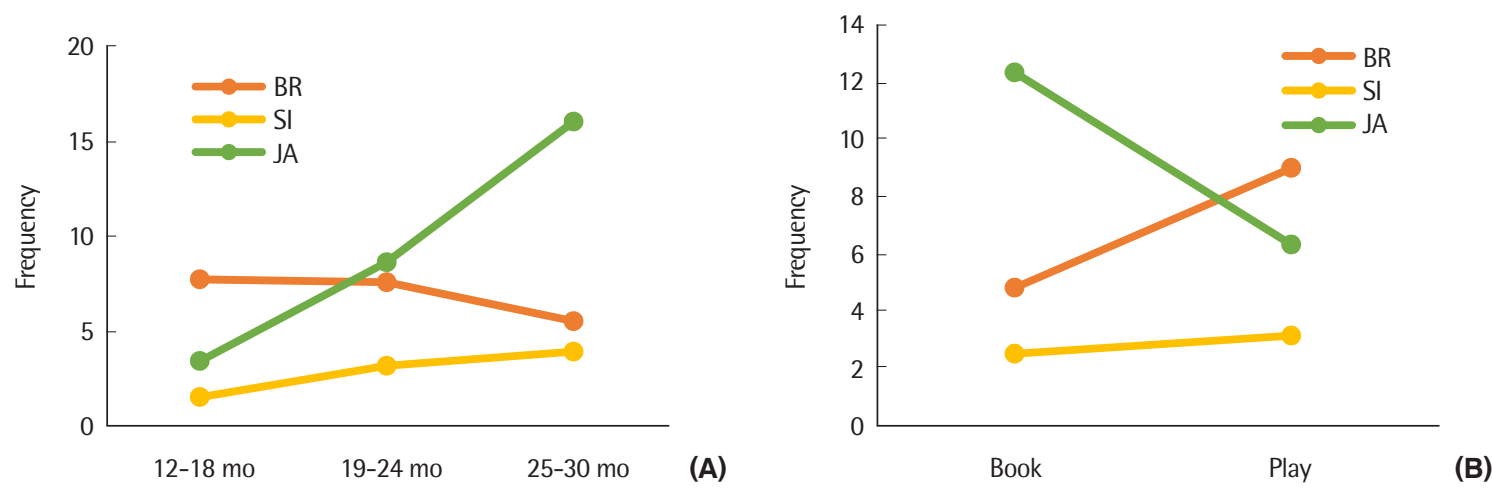

Figure 1. Interaction effects of age $\times$ communicative functions $(A)$ and interactional context $\times$ communicative functions (B). $\mathrm{BR}=$ behavior regulation; $\mathrm{SI}=$ social interaction; $\mathrm{JA}=$ joint attention.

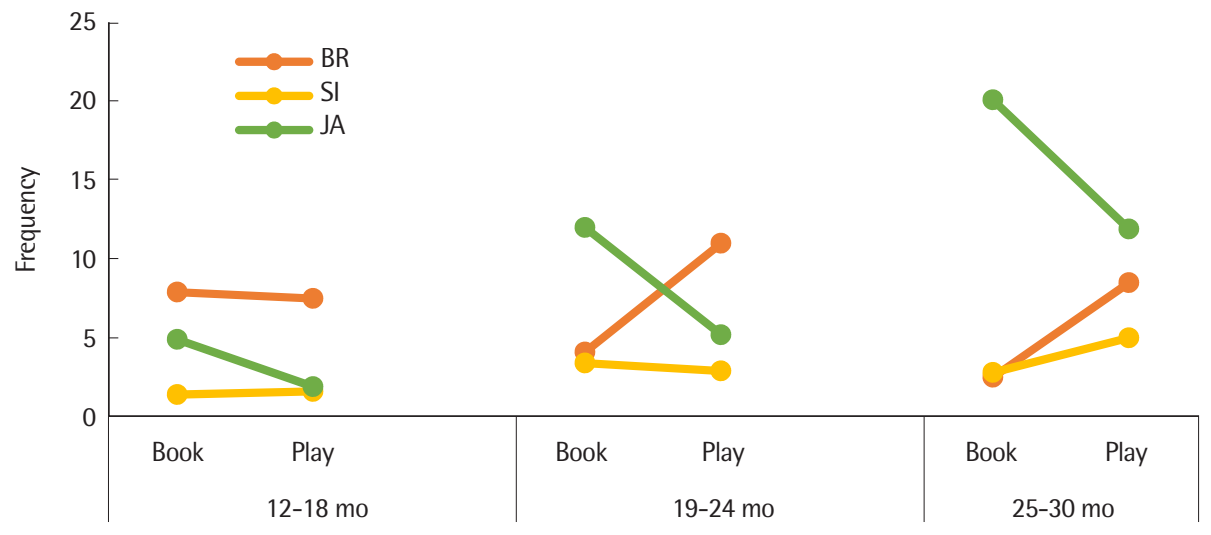

Figure 2. Interaction effects of age $\times$ communicative functions $\times$ interactional context.

적 기능을 7.70 회로 각각 $1.50,3.40$ 회로 측정된 사회적 상호작용과 동시주의 기능에 비해 유의하게 많이 보인 반면, 25-30개월에는 동 시주의 기능이 16.0 회로 각각 5.5 와 3.9 회를 보인 행동통제와 사회 적 상호작용 기능에 비해 유의하게 높은 빈도로 사용하였기 때문 에 나타났다(Figure 1A). 행동통제기능은 연령에 따라 7.70, 7.55, 5.50회로 24-30개월에 유의하게 감소하였으나, 반대로 동시주의기 능은 $3.40,8.60,16.0$ 회로 연령 증가와 더불어 유의하게 증가하였다. 사회적 상호작용기능은 $1.50,3.15,3.90$ 회로 19-24개월 이후에 약간 증가하였으나 유의한 차이가 없었다(Table 2).

상호작용 맥락 $\times$ 의사소통기능 간의 상호작용 효과는 행동통제 기능은 놀이에서 9.0 회로 책읽기의 4.83 회에 비해 유의하게 높은 빈 도를 보인 반면, 동시주의기능은 책읽기에서 12.33 회로 놀이 6.33 회 에 비해 유의하게 높은 빈도를 보였기 때문에 나타났다. 사회적 상 호작용기능은 책읽기와놀이 상황에서 차이가 없었다(Figure 1B).

연령 $\times$ 의사소통기능 $\times$ 상호작용 맥락 간의 상호작용 효과는 상 호작용 맥락과 의사소통기능 간의 상호작용 효과가 연령 증가에
따라 커졌기 때문에 나타났다(Figure 2). 즉, 행동통제기능은 책읽 기보다는 놀이에서, 반대로 동시주의기능은 놀이보다는 책읽기에 서 유의하게 증가하였는데, 이러한 경향이 나이가 제일 어린 12-18 개월 집단보다 19-24개월과 25-30개월 집단에서 크게 나타났다.

연령 $\times$ 상호작용 맥락 간에는 유의한 상호작용 효과가 나타나지 않았는데 이는 세 연령 집단 모두 의사소통행동의 빈도가 상호작 용 맥락에 따라서 유의하게 다르지 않았음을 의미한다. 12-18개월 은 책읽기에서 14.20 , 놀이에서 11.0 회, 19-24개월은 책읽기에서 19.50 , 놀이에서 19.10회, 25-30개월은 책읽기와 놀이 모두 25.40으로 비슷 한 빈도를 보였다(Table 2).

\section{논의 및 결론}

본 연구는 12-30개월의 영아를 12-18개월, 19-24개월, 25-30개월 의 세 연령 집단으로 나누어 연령에 따라 책읽기와 놀이, 두 가지 맥 락이 의사소통행동에 어떻게 영향을 미치는지를 확인하는 것을 
목적으로 하였다.

먼저 영아들의 의도적 의사소통행동은 연령과 의사소통기능 유 형에 따라서는 유의한 차이가 있었다. 즉, 의도적 의사소통행동이 연령 증가에 따라 유의하게 증가하였으며, 의사소통기능에 따라서 는 행동통제 기능의 빈도가 사회적 상호작용 기능의 빈도에 비해, 동시주의 기능의 빈도가 사회적 상호작용 기능의 빈도에 비해 유의 하게 높은 것으로 인해 나타났다. 이러한 결과는 영아의 의도적 의 사소통행동 발달에 대한 선행연구(Lee \& Lee, 2016; Wetherby et al., 1988)의 결과와 대체로 유사하다. 특히 의도적 의사소통행동이 12-18개월에 12.5회, 19-24개월에 19.3회, 25-30개월에 25.4회로 증 가하였는데, 이는 우리나라 영아들을 대상으로 분당 의도적 의사 소통행동이 12-18개월에는 1.38회, 19-24개월에는 2.22회, 25-30개 월에는 2.77회 정도로 증가하였다고 보고한 Lee와 Lee (2016)의 결 과와 유사한 수치로 의도적 의사소통행동 빈도를 초기 의사소통 행동 발달 지표로 고려할 수 있다고 논의한 선행연구를 지지한다.

반면, 의도적 의사소통행동 빈도는 상호작용 맥락에 따라서는 유의한 차이가 없는 것으로 나타났다. 기술통계를 보면 책읽기에서 19.70 회, 놀이에서는 18.50 회로 책읽기 조건에서 의사소통행동 빈 도가 약간 높았으나 통계적으로 유의한 차이는 아니었다. 이러한 결과는 본 연구와 마찬가지로 책읽기와 놀이 맥락에서 의사소통행 동을 비교한 후, 놀이 상황에서 영아의 의사소통행동 빈도가 유의 하게 높았다고 보고한 Kim 등(2015)의 결과와는 차이가 있다. Kim 등(2015)은 본 연구와는 다른 의사소통행동 분석기준을 사용하였 으며, 일반 영아만을 대상으로 한 본 연구와는 달리 말 늦은 영아와 일반 영아를 대상으로 하였고, 어머니가 상호작용 대상자로 참여하 였다는 점에서 본 연구와 차이가 있다. 이러한 요소들이 결과에 영 향을 미쳤을 가능성이 있다. 특히 본 연구에서는 상호작용 상대자 가 영아 행동에 미치는 요인을 통제하기 위하여 연구자가 직접 상 호작용 상대자로 참여한 반면, Kim 등(2015)의 연구에서는 어머니 의 상호작용 행동이 미치는 영향을 확인하기 위하여 상호작용 상 대자의 행동을 통제하지 않고 평소와 같이 자연스러운 상호작용을 요구하였다. 연구결과에서 어머니가 놀이보다 책읽기 맥락에서 영 아에게 언어적 자극을 주거나 의사소통행동을 유도하는 빈도가 놀이보다 책읽기 상황에서 유의하게 높은 것으로 나타났는데, 이러 한 부분이 맥락에 따른 결과에도 영향을 미쳤을 수 있다.

세 독립변인 간의 상호작용을 살펴본 결과에서는 연령과 의사소 통기능 간에, 상호작용 맥락과 의사소통기능 간에, 그리고 연령, 의 사소통기능, 상호작용 맥락 간에 유의한 상호작용 효과가 나타났으 며, 연령과 상호작용 맥락 간에는 유의한 상호작용 효과가 관찰되 지 않았다.
먼저 연령과 의사소통기능 간의 상호작용은 행동통제 기능은 24-30개월에 유의하게 감소하였으나, 반대로 동시주의 기능은 연령 증가와 더불어 유의하게 증가하였으며, 사회적 상호작용 기능은 19-24개월 이후에 약간 증가하였으나 유의한 차이가 없었던 것으 로 비롯되었다. 즉, 나이가 어린 12-18개월에는 행동통제 기능이 유 의하게 많이 나타난 반면, 나이가 많은 25-30개월에는 세 범주의 의 사소통기능 중에서 동시주의 기능이 가장 많이 나타났다. 이러한 결과는 나이가 어릴수록 행동통제 기능이 가장 많이 사용되다가 연령 증가와 더불어 언어능력이 향상됨에 따라 동시주의 기능의 빈 도가 유의하게 증가한다고 보고한 선행연구들(Chapman, 2000; Hong \& Kim, 2001; Lee \& Lee, 2016; Wetherby et al., 1988; Wetherby \& Prizant, 2002)과 같은 결과이다.

상호작용 맥락과 의사소통기능 간의 상호작용 효과는 놀이에서 는 행동통제 기능을, 책읽기에서는 동시주의 기능을 유의하게 높 은 빈도로 나타낸 것으로 인해 비롯되었다. 즉, 영아들은 책읽기 상 황에서는 동시주의 기능을 많이 사용하였고, 놀이 상황에서는 행 동통제 기능을 많이 사용하였다. 이러한 결과는 놀이 맥락에서는 사물을 사용하여 행동을 기반으로 상호작용을 하기 때문에 사물 이나 성인의 도움이 요구하는 행동통제 기능이 많이 사용된 것으 로 보이며, 책읽기 맥락에서는 놀이 맥락에 비하여 비교적 행동보 다는 그림을 통해 상호작용을 하므로 자신이 보고 있는 대상에 성 인의 관심을 요구하는 동시주의 기능 빈도가 유의하게 높은 것으 로 사료된다. 본 연구와 의사소통행동 분석기준은 달랐지만, 말 늦 은 영아를 대상으로 한 Kim 등(2015)도 책읽기 상황보다 놀이 상 황에서 요구하기 기능이 유의하게 높게 나타났다고 보고하였으며, 일반 유아를 대상으로 한 $\mathrm{Kim}$ (2000)의 연구에서도 책읽기 상황에 서 놀이 상황보다 모방하기, 명명하기가 유의하게 높았다고 보고하 여 대체로 본 연구와 유사한 결과를 보고한 바 있다. 또한 Yont 등 (2003)도 12 개월 영아가 책읽기, 놀이 상황에서 양육자와 상호작용 할 때에, 책읽기 상황에서 명명하기와 사물과 그림에 함께 주목하 는 동시주의기능 빈도가 유의하게 높았다고 유사한 결과를 보고하 였다. 이러한 결과를 종합할 때 영아의 의사소통행동의 기능은 상 호작용 맥락에 따라서 달라질 수 있다고 결론지을 수 있다. 이는 의 사소통행동 기능을 평가하거나 중재할 때 책읽기와 놀이 상황을 모두 고려해야한다는 시사점을 준다.

연령, 의사소통기능, 그리고 상호작용 맥락 간의 상호작용 효과 는 상호작용 맥락과 의사소통기능 간의 상호작용 효과가 연령 증가 에 따라 커졌기 때문에 나타났다. 즉, 행동통제 기능은 책읽기보다 는 놀이에서, 반대로 동시주의 기능은 놀이보다는 책읽기에서 유의 하게 증가하였는데, 이러한 경향이 나이가 제일 어린 12-18개월 집 
단보다 19-24개월과 25-30개월 집단에서 크게 나타났다. 이러한 결 과는 의사소통기능에 미치는 상호작용 맥락의 효과가 연령이 증가 함에 따라 더욱 명백해진다는 것으로 해석할 수 있다. 즉, 나이가 많 아질수록 의도적 의사소통행동의 빈도가 증가하며, 이와 더불어 상대적으로 어린 시기에는 행동통제기능이 많이 나타나고, 나이가 증가함에 따라 동시주의기능은 증가한다. 그리고 이와 더불어 행 동통제 기능은 놀이에서, 동시주의 기능은 책읽기에서 더 많이 사 용되는 경향이 두드러지게 되는 것이다.

반면, 연령과 상호작용 맥락 간에는 유의한 상호작용 효과가 나 타나지 않았는데 이는 세 연령 집단 모두 의사소통행동의 빈도가 상호작용 맥락에 따라서 유의하게 다르지 않았음을 의미한다. 앞 서 주효과에 대한 논의에서 영아의 의사소통행동 빈도에는 상호작 용 맥락이 영향을 미치지 않았다고 보고하였는데, 연령과 상호작 용 맥락 간의 상호작용 효과가 없었다는 결과는 세 연령 집단 모두 에서 의사소통행동 빈도 자체는 상호작용 맥락에 의해 영향받지 않았음을 보여 준다.

영아의 의도적 의사소통행동에 상호작용 맥락이 미치는 영향을 중심으로 본 연구의 결과를 종합하면 다음과 같다. 첫째, 영아의 의 사소통행동 빈도는 연령과 의사소통기능 유형에 따라 달라졌으나 상호작용 맥락에 따라서는 영향받지 않았다. 즉, 책읽기와 놀이 상 황에서 영아의 의사소통행동 빈도는 다르지 않았다. 둘째, 상호작 용 맥락은 영아의 의사소통기능 유형에는 영향을 미쳤다. 영아들 은 책읽기에서는 동시주의 기능을, 놀이에서는 행동통제 기능을 많이 사용하였으며, 이러한 경향은 연령이 증가함에 따라 더 뚜렷 하게 나타났다.

책읽기와 놀이는 영아들의 의사소통행동을 확인하고 촉진하는 데 흔히 사용되는 상호작용 맥락이다. 본 연구는 상호작용 맥락이 영아의 의도적 의사소통행동에 어떠한 영향을 미치는지, 그리고 그 러한 영향이 연령이 증가함에 따라 어떠한 차이를 갖는지를 확인 하였다. 이러한 결과는 행동 관찰을 통해 영아의 의사소통행동을 평가하거나 중재할 때 상호작용 맥락을 고려해야함을 시사한다.

\section{REFERENCES}

Bates, E., Camaioni, L., \& Volterra, V. (1975). The acquisition of performatives prior to speech. Merrill-Palmer Quarterly of Behavior and Development, 21, 205-226.

Bruner, J. (1981). The social context of language acquisition. Language \& Communication, 1, 155-178.

Calandrella, A. M., \& Wilcox, M. J. (2000). Predicting language outcomes for young prelinguistic children with developmental delay. Journal of Speech, Language, and Hearing Research, 43, 1061-1071.

Chapman, R. S. (2000). Children's language learning: an interactionist perspective. The Journal of Child Psychology and Psychiatry and Allied Disciplines, 41, 33-54.

Cho, M. R., \& Lee, Y. K. (2010). Communicative behaviors of toddlers with or without language delay. Korean Journal of Early Childhood Special Education, 10, 31-46.

Choi, J. J., \& Lee, Y. (2018). Communicative gestures in prelinguistic periods as predictors of later language development in Korean toddlers. Communication Sciences \& Disorders, 23, 11-19.

Dore, J. (1975). Holophrases, speech acts and language universals. Journal of Child Language, 2, 21-40.

Halliday, M. A. K. (1975). Learning how to mean: explorations in the development of language. London: Edward Arnold.

Hoff, E. (2006). How social contexts support and shape language development. Developmental Review, 26, 55-88.

Hong, G. H., \& Kim, Y. T. (2001). A longitudinal study of the acquisition of communicative intentions. Korean Journal of Communication \& Disorders, 6, 7-39.

Jang, H. S., Seo, S. J., \& Ha, J. Y. (2009). Developmental assessment for the early intervention program planning. Seoul: Hakjisa.

Kim, K. J. (2000). The toddler-mother interaction types and toddler language development. Unpublished doctoral dissertation (Doctoral dissertation). Duksung Women's University, Seoul, Korea.

Kim, R. Y., Lee, H. J., \& Lee, Y. K. (2015). The effect of book reading and play situations on the communicative acts of late-talking toddlers and their mothers. Journal of Speech-Language \& Hearing Disorders, 24, 15-27.

Lee, Y. J. (2006). The relationship among infants' communication aged 10 to 24 months, mothers' communication, and mother-infant interactive responsiveness (Doctoral dissertation). Yonsei University, Seoul, Korea.

Lee, Y., \& Lee, H. (2016). Development of intentional communicative behavior in Korean toddlers 12 to 30 months. Communication Sciences \& Disorders, 21, 553-566.

Lee, Y., \& Lee, H. J. (2013). Conversational turn-taking of toddlers with language delay. Special Education Research, 12, 357-377.

Lee, Y., \& Seol, Ah. (2012). Maternal communication style of toddlers with developmental language delay during toddler-mother interaction. Communication Sciences \& Disorders, 17, 263-273.

Wetherby, A. M., \& Prizant, B. M. (2002). Communication and symbolic be- 
havior scales: developmental profile. Baltimore, MD: Paul H Brookes Publishing.

Wetherby, A. M., \& Rodriguez, G. P. (1992). Measurement of communicative intentions in normally developing children during structured and unstructured contexts. Journal of Speech, Language, and Hearing Research, 35, 130138.

Wetherby, A. M., Cain, D. H., Yonclas, D. G., \& Walker, V. G. (1988). Analysis of intentional communication of normal children from the prelinguistic to the multiword stage. Journal of Speech, Language, and Hearing Research, $31,240-252$.

Yont, K. M., Snow, C. E., \& Vernon-Feagans, L. (2003). The role of context in mother-child interactions: an analysis of communicative intents expressed during toy play and book reading with 12-month-olds. Journal of Pragmatics, 35, 435-454. 
Appendix 1. 의도적 의사소통행동 분석 기준

\begin{tabular}{|c|c|c|}
\hline 유형 & 정의 & 예 \\
\hline 의도적 의사소통행동 & $\begin{array}{l}\text { 다른 사람에게 분명하게 의도를 담아 나타낸 언어적 비언어적 행동. 언 } \\
\text { 어적 비언어적 행동이 시선, 자세, 몸짓 등을 통해 명확히 상대방을 향 } \\
\text { 한 것이어야 함. } \\
\text { 의도적 의사소통행동은 행동통제, 사회적 상호작용, 동시주의 기능 중 } \\
\text { 하나로 분류됨. }\end{array}$ & $\begin{array}{l}\text { 상대방을 바라보거나 혹은 상대방을 향한 자세로 의도를 나타내는 몸 } \\
\text { 짓 또는 언어를 사용함. }\end{array}$ \\
\hline \multicolumn{3}{|l|}{ 의사소통 기능 } \\
\hline 행동통제 & $\begin{array}{l}\text { 특정한 결과를 얻기 위한 목적으로 상대방의 행동을 통제하는 것과 관 } \\
\text { 련된 기능. 사물 및 행동 요구하기, 사물 및 행동 거부하기가 포함됨. }\end{array}$ & $\begin{array}{l}\text { 엄마가 들고 있는 포크를 향해 손을 뻗음. 시선이나 자세가 상대방을 } \\
\text { 향하여야 함. } \\
\text { 관습적 형태의 몸짓 또는 언어 사용이 나타나야 함. }\end{array}$ \\
\hline 사회적 상호작용 & $\begin{array}{l}\text { 상대방의 주의를 자기에게 유도하거나 유지하기 위한 기능. 인사하기, } \\
\text { 부르기, 보여주기가 포함됨. }\end{array}$ & $\begin{array}{l}\text { 자기를 바라보게 하려는 의도로 엄마를 향해 소리를 지르거나 언어를 } \\
\text { 표현함. 시선이나 자세가 상대방을 향하여야 함. }\end{array}$ \\
\hline 동시주의 & $\begin{array}{l}\text { 상대방의 주의를 제 } 3 \text { 의 사건 혹은 사물로 유도하거나 유지하기 위한 기 } \\
\text { 능. 언급하기와 질문하기가 포함됨. }\end{array}$ & $\begin{array}{l}\text { 바닥에 쏟아진 우유를 손가락으로 가리키며 엄마를 바라봄. 또는 소리 } \\
\text { 를 내거나 언어를 표현함. 몸시선이나 자세가 상대방을 향하거나 시 } \\
\text { 선의 이동이 있어야 함. }\end{array}$ \\
\hline
\end{tabular}

Lee \& Lee (2016)의 내용을 수정·발췌함. 


\section{국문초록}

\section{상호작용 맥락이 영아의 의도적 의사소통행동에 미치는 영향: 책읽기와 놀이를 중심으로 이다예 $\cdot$ 이윤경 \\ '한림대학교 보건과학대학원 언어병리학과, ${ }^{2}$ 한림대학교 언어청각학부}

배경 및 목적: 본 연구는 책읽기와 놀이 상황에 따라 영아들의 의도적 의사소통행동이 어떻게 달라지는지를 살펴보고자 하였다. 방법: 연구에는 12-18개월, 19-24개월, 25-30개월의 세 연령집단의 영아가 각각 10명씩, 총 30명이 참가하였다. 각 영아를 대상으로 책 보기와 놀이 조건에서 상호작용 행동을 10 분씩 분석하였다. Lee와 Lee (2016)의 기준과 정의를 따라 의도적 의사소통행동 빈도와 기능별 빈도 를 측정하였다. 결과: 의도적 의사소통행동 빈도는 연령에 따라 유의하게 증가하였으나 상호작용 조건에 따라서는 유의한 차이가 없었 다. 의사소통기능 빈도는 연령 및 조건과 유의한 상호작용효과를 보였다. 즉, 책읽기에서는 동시주의 기능이, 놀이에서는 행동통제 기능 이 많이 나타났는데, 이러한 경향이 연령이 증가함에 따라 더욱 두드러졌다. 논의 및 결론: 본 연구는 영아의 의사소통행동이 상호작용 맥락에 의해 영향받을 수 있다는 사실을 확인하였으며, 이러한 결과는 영아의 의사소통행동 평가 및 중재 시 상호작용 맥락을 고려해 야한다는 시사점을 제공한다.

핵심어: 영아, 의도적 의사소통행동, 상호작용 맥락, 책읽기, 놀이

\section{참고문헌}

김금주(2000). 영유아-어머니의 상호작용 유형과 영유아의 언어 발달에 관한 연구: 놀이, 일상, 책 읽어주기 상황을 중심으로. 덕성여자대학교 대학원 박사학위논문.

김란영, 이효주, 이윤경(2015). 책 읽기와 놀이 조건이 말 늦은 영유아와 어머니의 의사소통 행동 에 미치는 영향 언어치료연구, 24, 15-27.

이유진(2006). 10-24개월 영아의 의사소통과 어머니의 의사소통 및 어머니-영아의 상호반응성 간의 관계. 연세대학교 대학원 박사학위논문. 이윤경, 설아영(2012). 영유아-어머니 상호작용에서의 언어발달지체 영유아 어머니 의사소통 행동 특성. 언어청각장애연구, 17, 263-273.

이윤경, 이효주(2013). 표현언어발달지체 영유아의 대화차례 주고받기 특성. 특수교육, 12, 357-377.

이윤경, 이효주(2016). 12-30개월 영유아의 의도적 의사소통 행동 발달. 언어청각장애연구, 21, 553-566.

장혜성, 서소정, 하지영(2010). 영아선별 교육진단검사(Developmental assessment for the Early intervention Program planning). 서울: 학지사. 조미라, 이윤경(2009). 언어발달지체 유아와 일반 유아의 의사소통 행동 비교. 유아특수교육연구, 10,31-46.

최진주, 이윤경(2018). 언어이전 시기의 의사소통적 몸짓 사용이 24 개월 언어발달에 미치는 영향에 관한 종단연구. 언어청각장애연구, 23, 11-19. 홍경훈, 김영태(2001). 아동의 의사소통 의도 습득에 대한 종단연구. 언어청각장애연구, 6, 7-39. 